\title{
US law delays drug testing
}

\section{Washington}

Plans by the National Institute for Allergy and Infectious Diseases (NIAID) to speed clinical trials of potential treatments for some of the consequences of acquired immune deficiency syndrome (AIDS) have been thwarted by a legal technicality. Nine clinical research centres around the United States that had been awarded "master agreements" to conduct phase II clinical trials of antiviral drugs and therapies for opportunistic infections to which AIDS patients are prone have been told their agreements will not be honoured because of new government contracts. Future trials will be handled with standard

\section{Beckman bucks}

\section{Washington}

ThE University of Illinois is to receive $\$ 40$ million, the largest gift ever by an individual to a public university, from Arnold Beckman, founder of Beckman Instruments Inc. The money will be used to establish a multidisciplinary research institute consisting of two centres, one focusing on materials and computing science and the other on biology, behaviour and cognition.

Research at each centre will begin with problems at the atomic and molecular level and proceed through systems of increasing complexity. The ultimate aim is to understand "intelligence", says Theodore Brown, chancellor for research at the university. Emphasis will be placed on a comparison of complex integrated electronics and artificial intelligence systems with biological systems.

The university sees the centre as the largest-scale attempt yet to bridge the gap between the physical and biological sciences in one institution. A grant of $\$ 10$ million by the state of Illinois will make possible a 1986 start on construction at the site, which should be completed by 1988 . The state has also guaranteed the institute $\$ 2$ million a year in perpetuity for running costs and the launch of research programmes. The bulk of the financial support for running the institute is expected to come from outside sources. A director should be appointed within six to nine months. Beckman, now 85 , began the company of which he remains chairman in 1935, when a member of the faculty of the California Institute of Technology. His first product was a $p H$ meter, but by the time the company was merged with Smith Kline Corporation in 1982, Beckman was selling more than $\$ 1,000$ million worth of instruments each year. There seems to have been some genteel competition for Mr Beckman's generosity between Caltech and Illinois, where Beckman took his first degree (in physical chemistry) in 1923.

Maxine Clarke procedures that will lead to routine delays of about two months, according to Carl Fretts, director of NIAID's division of contracts and grants.

So far, clinical trials of potential AIDS therapies are still in the phase I stage, aimed at establishing safety and using small numbers of patients. Under the master agreement scheme, testing centres able to demonstrate adequate facilities and expertise for controlled phase II trials were certified in advance by NIAID. When trials then became necessary, the best-qualified centres could be quickly selected and protocols drawn up with a minimum of delay. The scheme freed NIAID from the requirement to advertise each trial contract for 30 days before considering proposals; it would also escape having to consider proposals from unqualified institutions. It was "a perfect mechanism", according to Harry Haverkos, AIDS project officer for NIAID. Similar arrangements have been used in the past for trials of anti-cancer drugs.

To qualify for a masters agreement, institutions had to produce "an enormous amount of information", according to one disgruntled researcher. Centres were required to show that they had sufficient numbers of patients, adequate laboratory expertise and facilities for handling large amounts of data. The nine successful centres were selected last May (from a considerably larger number of applicants).

Only one contract for an actual trial had been awarded when NIAID realized that the agreements are apparently illegal under the Competition Act, which came into effect in April. The scheme is now "in limbo", according to Haverkos. The single contract awarded under the scheme was to Robert Holzman of New York University Medical Center for a controlled trial of the effectiveness of trimethoprimsulfamethoxazole and Fansidar in preventing recurrences of Pneumocystis infections. Holzman is now waiting for delivery of the drugs to start the trial.

George Galasso, coordinator of AIDS clinical trials for the National Institutes of Health, "does not believe" the legal foulup has delayed getting trials under way, since many institutions are willing to proceed with trials even without a formal source of funds. Others, including some researchers, disagree. Haverkos would not exclude the possibility that trials have been delayed, although "we couldn't have got more than four or five under way" by now even if all had gone according to plan.

According to Carl Fretts, the Competition in Contracts Act was passed by Congress primarily to curtail abuses by defence contractors and was never intended to apply specifically to clinical trials. Through the Department of Health and Human Services, NIAID will bring the matter up shortly with the Civilian Agencies Acquisition Council, which wrote the implementing regulations, and seek to have the regulations altered so that masters agreements are permitted. Fretts points out that such agreements do not stifle competition because research centres have to reapply once a year. In the meantime, NIAID will by next month be awarding standard contracts for the trials, and special dispensations to speed future rounds of the contract procedure are being sought.

Tim Beardsley

Plant protection

\section{US patent rights march on}

Washington

THE US Board of Patent Appeals and Interferences has ruled, in what is hailed as a "landmark decision", that seeds, plants and plant tissue cultures can be protected under the 1952 Patent Act. The decision reverses existing government policy and is expected greatly to increase incentives for research in plant biotechnology.

The board's ruling was a response to an appeal by Molecular Genetics Inc. which has modified maize plants to produce extra tryptophan, an amino acid that has often to be added as a supplement to animal feed. Tryptophan-enriched maize used as animal feed would avoid the need for supplements.

Before the recent ruling, only limited patent protection could be obtained for plants. The 1930 Plant Patent Act covered asexually reproduced plant varieties, and the 1970 Plant Variety Protection Act covered single novel varieties of sexually reproducible plants, but neither has been considered adequate by the plant biotechnology industry. The hybrid offspring of a patented plant variety and a standard strain would not, for example, be protectable under the 1970 act

Because of the new ruling, plant biotechnology will receive "the same generic scope of protection as other inventions", according to Leslie Misrock, patent attorney for Molecular Genetics. Companies that patent novel seeds, plants or tissue culture will be able to prevent competitors from making, using or selling the protected item - which includes using it for breeding. The effect for Molecular Genetics will be that, once its patent is issued, not only its original tryptophanenriched maize seed but all subsequent varieties bred from it will be protected.

The company intends to produce a range of tryptophan-enriched maize seed with different varieties for different climatic conditions. Misrock said that the implications for the seed industry of the new decision are "enormous". It will, he said, transform it" from a speciality industry to a commodity industry". Tim Beardsley 